\title{
PENGARUH KOMPETENSI DAN PENGEMBANGAN KARIR TERHADAP PRODUKTIVITAS KERJA DI PERUM JAMKRINDO (Jaminan Kredit Indonesia) SURABAYA
}

\author{
Deni Subiantoro1. I Ketut Surabagiarta², Evita Purnaningrum³ \\ Universitas PGRI Adi Buana Surabaya1,2,3 \\ denisubiantoro75@gmail.com
}

\begin{abstract}
ABSTRAK
Pengkajian yang dilakukan guna mengetahui pengaruh kompetensi dan pengembangan karir terhadap produktivitas kerja di perum JAMKRINDO (Jaminan Kredit Indonesia) Surabaya. Dalam pengkajian Populasi yang digunakan yaitu semua pegawai di perum JAMKRINDO (Jaminan Kredit Indonesia) Surabaya yang berjumlah 185 . Sampel yang digunakan dalam pengkajian yaitu 70 responden menggunakan teknik sampling purposive. Karena didalam pengkajian ini peneliti hanya dapat melakukan penelitian pada satu divisi saja yaitu bagian karyawan tetap perusahaan. Dalam pengkajian ini jenis data yang digunakan yaitu data primer, dengan metode yang regresi linier berganda. Hasil pengkajian ini secara parsial dan simultan kompetensi dan pengembangan karir berpengaruh signifikan terhadap produktivitas kerja di perum di perum JAMKRINDO (Jaminan Kredit Indonesia) Surabaya.
\end{abstract}

Kata Kunci : Kompetensi, Pengembangan Karir, Produktivitas Kerja.

\section{ABSTRACT}

Assessment conducted to determine the effect of competence and career development on work productivity at JAMKRINDO (Indonesian Credit Guarantee) surabaya. In the assessment of the population used are all employees all employees of JAMKRINDO (Indonesian Credit Guarantee) surabaya which amounts to 185. The sample used in the assessment is 70 respondents using purposive sampling technique. Because in the study, researchers can only conduct research in one division, namely the permanent employees of the company. In this study the type of data used is primary data, with multiple liniear regression methods. The results of this study are partially and simultaneously competence and career development significantly influence work productivity in public companies JAMKRINDO (Indonesian Credit Guarantee) surabaya.

Keywords :Competence, career development, work productivity 


\section{PENDAHULUAN}

Didalam dunia kerja sekarang ini sangat membutuhkan sumber daya manusia yang berfikir cerdas, maju, inovatif dan mampu berkarya untuk dapat menghadapi kemajuan zaman. Manajemen sumber daya manusia menggangap bahwa pegawai adalah salah satu aset utama dalam organisasi yang mestinya dikelola dengan baik. Sehingga keberadaan tersebut sangat berharga untuk perusahaan agara dapat mengelola, mengatur, mengurusi dan memakai. Berbenah dalam mengelola pegawai sebagai aset penting dalam sebuah perusahaan. Adapun inovasi yang dapat dilakukan yaitu mulai dari proses perekrutan karyawan sehingga pengembangan karir untuk menjadi emimpin perseorangan dan untuk mendapatkan karyawan yang berkualitas. (uww.kata.data.com)

Perum JAMKRINDO (Jaminan kredit indonesia) kanwiil VI surabaya dengan karyawan yang berjumlah 185 selalu menjaga intregitas, produktivitas kerja bank dan keunggulan yang kompetitif dengan melakukan peningkatan pelayanan terbaik terhadap nasabahnya. Dari aspek kinerja karyawan perum JAMKRINDO (Jaminan kredit indonesia) kanwil VI surabaya terus mengalami pertumbuhan yang cukup signifikan di dalam dunia bisnis perbankan, terdapat persaingan yang sangat ketat sehingga manajemen bank harus bisa meningkatkan jasa pelayanan yang lebih baik terhadap nasabahnya agar terus maju. Sebagai salah satu usaha untuk mengembangkan jasa pelayanan dala suatu perusahaan yang berhubungan dengan produktivitas kerja karyawan dengan tolak ukur penilaian kinerja berdasarkan kompetensi kerjanya. Adapun pelatihan kerja yang bisa menyangkut peningkatan kapasitas karyawannya. Seperti halnya perum JAMKRINDO kanwil VI surabaya mengadakan tes kerja yang secara online setiap satu bulan sekali untuk dapat mengetahui kualitas yang dimiliki oleh setiap karyawan. Selain pelatihan secara berskala, budaya kerjapun harus diperbaiki, salah satunya adalah menanamkan kompetensi dan pengembangan karir. (www.kompas.com).

Sehubungan dengan permasalahan diatas, peneliti dapat merumuskan pertanyaan peneliti guna mengetahui terdapatnya pengaruh positif antara kompetensi terhadap produktivitas kerja di perum JAMKRINDO (Jaminan kredit indonesia) Surabaya dan pengembangan karir berpengaruh terhadap produktivitas kerja karyawan perum JAMKRINDO (Jaminan Kredit Indonesia) Surabaya, dan kompetensi dan pengembangan karir berpengaruh positif terhadap produktivitas di perum JAMKRINDO surabaya.

Berdasarkan latar belakang diatas peneliti memberikan tujuan khusus agar dapat mengetahui serta mengevaluasi permasalahan tersebut dan peneliti tertarik untuk mengakat judul penelitian diatas.

\section{TELAAH PUSTAKA}

\section{Kompetensi}

Menurut Spencer (2017:203), kompetensi merupaka sikap yang menunjukan dan keefektivan seseorang dalam pekerjaanya. Sementara itu Boulter dkk (2017:203), kompetensi merupakan karakter mendasar dari seseorang yang dapat memberikan hasil kerja yang baik didalam kemampuan dalam melakukan pekerjaanya.

Dari beberapa para pakar mengatakan, maka kompetensi kerja kerja adalah karakteristik seseorang yang selalu berkesinambungan dengan kemampuan kerja seseorang dalam pekerjaanya, peran, atau situasi tertentu. Guna untuk dapat memajukan produktivitas dalam mencapai keberhasilan perusahaan.

Menurut Zwell dalam wibowo (2017:283) faktor keyakinan dan nilai - nilai, keterampilan, pengalaman, kepribadian yang baik, motivasi, kecerdasannya dan budaya organisasi merupakan faktor yang dapat mempengaruhi kompetensi.

Gordon (2017:204), di dalam penelitian ini kompetensi kerja meliputi enam indikator yaitu : sikap, nilai, minat, pengetahuan, pemahaman, kemampuan, 


\section{Pengembangan Karir}

Proses karir yaitu suatu proses yang sengaja dilakukan perusahaan unruk membantu karyawannya agar lebih meningkatkan jenjang karirnya.

Menurut Handoko (2017:160), karir digunakan untuk menunjukkan seorang pada setiap karakter atau status mereka, sedangkan menurut Gibson (2017:161), pengembangan karir merupakan perilaku serta sikap yang berhubungan akan pengalaman dalam pekerjaan sepanjang hidup dari seseorang dari awal kerja hingga sampai saat ini.

Berdasarkan definisi diatas bahwa pengembangan karir seseorang dapat digunakan dalam mencapai suatu tujuan organisasi perusahaan.

Menurut Kasmir (2018:157), faktor yang dapat berpengaruh terhadap pengembangan karir seseorang adalah kinerja, motivasi kerja, komitmen, kedisiplinan, kompensasi, loyalitas, pendidikan dan kepemimpinan, upaya kerja dan semangat kerja yang tinggi.

Menurut Tohardi dalam Sutrisno (2017:166), adapun indikatornya Pengembangan karirdalam sebagai berikut : pendidikan, prestasi kerja sikap atasan dan rekan kerja, pengalaman

\section{Produktivitas Kerja}

Menurut Tohardi (2017:100), Produktivitas kerja adalah sikap pikiran yang iningin mencari perbaikan akan apa yang sudah dilakukan. Sehingga mempunyai keyakinan untuk pekerjaanya yang jauh lebih baik hari sebelumnya.

Kusrianto (2017:102), produktivitas kerja adalah tolak ukur dari apa yang sudah di raih menggunakan peran dan tenaga kerja dalam hitungan waktu, sehingga lebih efisien, efektif serta berkualitas dalam penggunaan sumber daya.

Dari beberapa difinisi itu produktivitas kerja di dalam penelitian ini merupakan seseorang karyawan harus melaksanakan dan mengerjakan tugasnya dengan baik,serta efisien dan efektik dalam upaya meningkatkan produktivitas kerjanya.

Sutrisno (2017:104), bahwa di dalam penelitian ini produktivitas meliputi : kemampuan, meningkatkan hasil yang dicapai, semangat kerja, pengembangan diri, mutu, efisiensi.

\section{HIPOTESIS}

Berdasarkan kerangka berfikir dan teori, maka hipotesis penelitian ini dapat dibuat sebagai berikut :

$\mathrm{H}_{1} \quad$ : Kompetensi mempengaruhi terhadap produktivitas kerja secara positif

$\mathrm{H}_{2} \quad$ : Pengembangan karir mempengaruhi terhadap produktivitas kerja secara positif

$H_{3} \quad$ : Kompetensi serta pengembangan karir mempengaruhi terhadap produktivitas kerja secara simultan

\section{METODE}

Di dalam penelitian ini dilakukan diperum JAMKRINDO (Jaminan Kredit Indonesia) Surabaya dengan populasi seluruh karyawan yang berjumlah 185 dan sampel yang digunakan hanya pada satu devisi yaitu karyawan tetap dengan sebanyak 70 responden. Karena dalam pengkajian ini peneliti hanya dapat menggunakan pengkajian hanya satu devisi saja yaitu bagian karyawan tetap perum JAMKRINDO ( jaminan kredit indonesia) surabaya. dan analisis regresi linier berganda,uji $t$ dan uji $F$ serta koefisien determinasi $\left(\mathrm{R}^{2}\right)$ digunakan untuk sebagai analisis data. pengujian hipotesis menggunakan pengujian asumsi klasik, Sedangkan pengelolaan data didalam penelitian ini dngan penggunaan SPSS versi 25 for windows. 


\section{Uji Instrumen Penelitian \\ Uji Validitas}

Yaitu kompetensi $\left(\mathrm{X}_{1}\right)$ dengan 12 item pernyataan, pengembangan karir $\left(\mathrm{X}_{2}\right)$ sebanyak 8 item pernyataan dan variabel terikat produktivitas kerja $(Y)$ berjumlah 12 item pernyataan. Berdasarkan semua pernyataan pada variabel independen dan variabel dependen tersebut dinyatakan valid di karenakan nilai rhitung>rtabel dengan taraf sig untuk r tabel 0,05 hitung dan r hitung 0,2319,

\section{Uji Reliabilitas}

Pada pengkajian ini dikatakan reliabel karena nilai reliabilitas yang dilihat dari suatu indikator kuisioner nilai dari nilai Cronbach Alpha, > 0,6 maka variabel tersebut adalah reliabel.

Tabel 1

\begin{tabular}{|c|c|c|}
\hline Variabel & $\begin{array}{c}\text { Cronbach } \\
\text { Alpha }\end{array}$ & Keterangan \\
\hline Kompetensi (X1) & 0,807 & Reliabel \\
\hline $\begin{array}{c}\text { Pengembangan } \\
\text { Karir (X2) }\end{array}$ & 0.829 & Reliabel \\
\hline Produktivitas Kerja $(\mathrm{Y})$ & 0,836 & Reliabel \\
\hline
\end{tabular}

\section{HASIL PENELITIAN}

Adapun karakteristik responden yang digunakan sebagai sampel penelitian sebagai berikut :

Berdasarkan jenis kelamin dari 70 responden karyawan tetap erum JAMKRINDO (Jaminan kredit indonesia) surabaya dapat diketahui sebanyak 42 responden atau $60 \%$ berjenis kelamin perempuan, 28 responden atau $40 \%$ berjenis kelamin laki - laki.

Berdasarkan usia sebanyak 3 responden atau 4,3\% berusia 30-32 tahun, 11 responden atau 15,7\% berusia 33-35 tahun, 11 atau 15,7\% berusia 36-38, 18 atau $25,7 \%$ berusia 39-41, sebanyak 7 atau $10 \%$ berusia $42-$ 44, 15 atau 21,4\% berusia 45-47, dan sebanyak 5 atau 7,2\% berusia $48-50$.

Berdasarkan pendidikan terakhir sebanyak 49 atau $70 \%$ adalah strata 1 dan sebanyak 21 atau $30 \%$ adalah diplomat.

Berdasarkan masa kerja diketahui sebanyak 24 atau 34,4\% mempunyai masa kerja 5 tahun, 11 atau 15,7\% masa kerja 6 tahun, 17 atau 24,3\% masa kerja 7 tahun, sebanyak 18 atau 25,7\% masa kerja 8 tahun.

\section{Analisis Regresi Linier Berganda}

Secara sistematis hasil analisis ini dapat ditulis persamaannya :

$\mathrm{Y}=18,945+0,300 \mathrm{X}_{1}+0,429 \mathrm{X}_{2}+\mathrm{e}$

1. Nilai dari konstanta 18,945 dinyatakan apabila variabel bebas yaitu kompetensi (X1) dan pengembangan karir (X2) dianggap konstan, sehingga produktivitas kerja mendapatkan yang tinggi tanpa kedua variabel bebas yang telah disebutkan maka estimasi produktivitas kerja belu $\mathrm{m}$ ada tanda - tanda perubahan berpengaruh.

2. Nilai koefisien variabel kompetensi (X1) sebesar 0,300 , koefisien regresi (b1) sebesar 0,300 memberikan arti bahwa kompetensi dalam penilaian karyawan ada penigkatan sebesar satu satuan maka produktivitas kerja dapat meningkat 0,300 dengan anggapan variabel kompetensi dianggap konstan (nol). 
1. Nilai koefisien variabel pengembangan karir (X2) sebesar 0,429 , koefisien regresi (b2) sebesar 0,429 memberikan arti bahwa pengembangan karir dalam penilaian karyawan ada peningkatan sebesar satu satuan maka produktivitas kerja dapat meningkat 0,429 dengan anggapan variabel pengembangan karir dianggap konstan (nol).

Tabel 2

\begin{tabular}{|c|c|c|}
\hline \multicolumn{2}{|c|}{ Variabel } & $\begin{array}{c}\text { Unstandarized } \\
\text { Coefficients }\end{array}$ \\
\hline & $\mathrm{B}$ & Std. Error \\
\hline $\begin{array}{c}\text { (Constant) } \\
\text { Kompetensi }\end{array}$ & 18,945 & .951 \\
\hline $\begin{array}{c}\text { Pengembangan } \\
\text { Karir (X2) }\end{array}$ & .300 & .112 \\
\hline
\end{tabular}

\section{Pengujian Hipotesis \\ Koefisien Determinasi $\left(\mathbf{K}_{2}\right)$}

Bernilai sebesar 0,158 atau 15,8\%. Menunjukkan bahwa kemampuan menjelaskan variabel independen (X1) serta (X2) terhadap variabel terikat (Y) ditunjukkan nilai 15,8\% sisanya 84,2\% dijelaskan dari variabel lain diluar 2 variabel bebas tersebut.

Uji t

Berdasarkan dari hasil pengujian uji t dapat diketahui hasilnya:

1. Dari hasil perhitungan uji t diatas dapat dijelaskan bahwa variabel $(X 1)$ terdapat pengaruh sig dimana menunjukkan nilai 2.690. hal ini sesuai dengan hipotesis1 menunjukan kompetensi terdapat pengaruh produktivitas kerja perum JAMKRINDO (Jaminan Kredit Indonesia) Surabaya.

2. Dari hasil perhitungan diatas dijelaskan bahwa variabel $\mathrm{X} 2$ terdapat pengaruh sig dimana menunjukan nilai 2,312. Hal tersebut sesuai dengan hipotesis 2 menunjukkan pengembangan karir terhadap pengaruh produktivitas kerja perum JAMKRINDO (Jaminan Kredit Indonesia) Surabaya.

Uji F

Berdasarkan dari tabel uji F diketahui bahwa nila sig. 0,001 Sehingga dapat disimpulkan bahwa hipotesis ke 3 terdapat adanya pengaruh antara kompetensi dan pengembangan karir simultan terhadap produktivitas kerja Perum JAMKRINDO (Jaminan Kredit Indonesia) Surabaya.

\section{Uji Asumsi Klasik}

Uji Normalitas

Dari tabel uji normalitas diketahui bahwa nilai asymp.sig 0,002 sehingga asumsi norml terpenuhi yang artinya data hasil dari kuisioner yang digunakan didalam penelitian ini, sehinga dapat memenuhi syarat untuk dianalisis.

Tabel 3

\begin{tabular}{|c|c|} 
& tandardized Residual \\
\hline $\mathrm{N}$ & 70 \\
\hline Test Statistic & .072 \\
\hline Asymp. Sig. (2-tailed) & $.200^{c}$ \\
\hline
\end{tabular}

\section{Uji Multikolinieritas}

Berdasarkan hasil ini masing - masing nilai memiliki nilai VIF 1.025>0.01 yang artinya sehingga semua variabel idependent dan variabel dependent bebas dari masalah multikolinearitas. 
Tabel 4

\begin{tabular}{|l|c|c|}
\hline \multirow{2}{*}{ Variabel Independen } & \multicolumn{2}{|c|}{ Coliniarity statistics } \\
\cline { 2 - 3 } & Tolerance & \\
\hline Kompetensi & .975 & 1.025 \\
\hline Pengembangan Karir & .975 & 1.025 \\
\hline
\end{tabular}

\section{Uji Heteroskedastisitas}

Berdasarkan dari hasil pengujian yang dilakukan menguunakan scaterplot, membuktikan bahwa tidak ada gejala heteroskedatisitas, karenakan titk - tik dari arah atas ke arah bawah atau dari 0 ke sumbu Y.

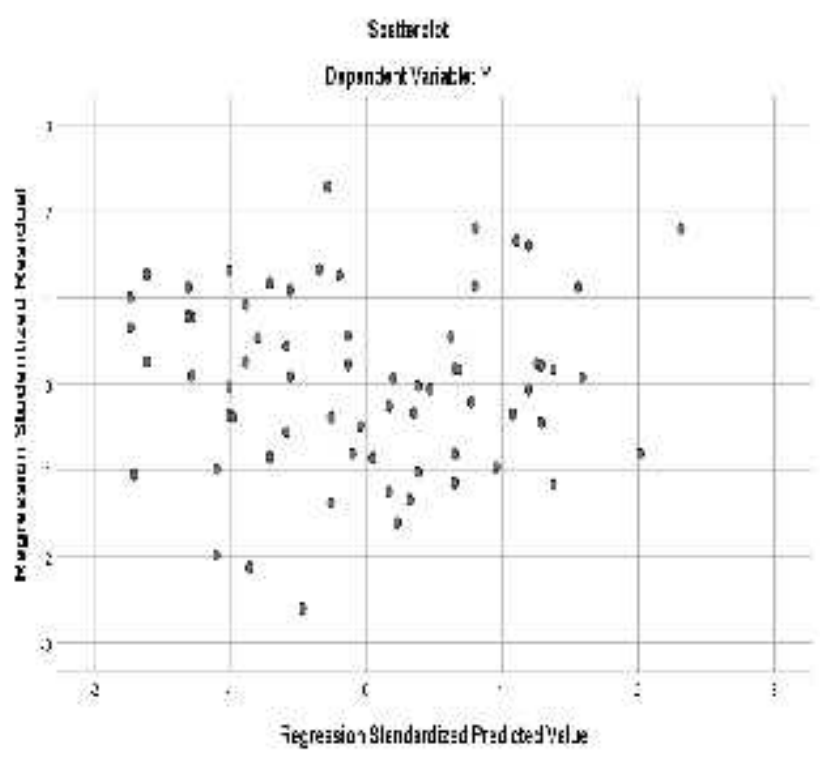

\section{Uji Autokorelasi}

Berdasarkan uji ini menggunakan uji Durbin Watson. Dari hasil pengujian tersebut dapat dilihat terdapat nilai 1.983>DU 1.650, sehingga dipenelitian ini tidak terjadi autokorelasi.

\section{PEMBAHASAN}

Berdasarkan nilai tersebut dapat ditarik kesimpulan bahwa kompetensi memiliki Pengaruh terhadap produktivitas kerja diperum JAMKRINDO (Jaminan kredit indonesia) Surabaya yang memiliki nilai thitung 2.690 dan nilai sig $0.009<0.05$.

Hasil ini sejalan pernah dipakai oleh axcel tumiwa dkk (2017) " pengaruh teknologi informasi, lingkungan kerja dan kompetensi terhadap produktivitas karyawan. Study pada kantor pusat bank sulutgo".

Berdasarkan nilai tersebut, dapat ditarik kesimpulan bahwa pengembangan karir berpengaruh terhadap produktivitas kerja karyawan di Perum JAMKRINDO (jaminan kredit indonesia) surabaya. Dimana menunjukkan nilai 2.312 dan nilai sig $0.024<0.05$.

Hasil diatas juga sejalan pernah dilakukan oleh dudung abdullah (2016) judul "pengaruh pengembangan karir dan kepuasan kerja terhadap produktivitas kerja karyawan. Study di pt. Gistex garmet indonesia kabupaten majalengka". 
Dari pengujian uji t serta uji F diketahui bahwa bernilai sebesar 7.455. sehingga dapat diartikan bahwasanya terdapat pengaruh simultan kompetensi dan pengembangan karir terhadap produktivitas kerja diperum JMAKRINDO (Jaminan kredit indonesia) Surabaya.

Hasil itu pernah digunakan oleh samsul bahri (2016) deng menggunakan jdul pengaruh pengembangan karir dan kompetensi terhadap produktivitas kerja serta implikasinya pada kinerja pegawai dinas pu bina marga wilayah kerja sumatera selatan. Dimana hasil penelitian menyatakan bahwa pengembangan karir dan kompetensi secara simultan berpengaruh terhadap produktivitas kerja karyawan.

\section{SIMPULAN}

Dari hasil tersebut data penelitian yang diajukan dalam pengkajian ini, dengan memakai data primer di Perum JAMKRINDO, maka kesimpulanya bahwa hasil perhitungan nilai statistik uji $F$ mengenai Kompetensi dan pengembangan karir sehingga scra simultan berpengaruh signifikan terhadap produktivitas kerja. Pengujian hipotesis ini dilakukan dengan menggunakan uji $F$ yang menunjukkan nilang $F$ hitung 0,009 $<0,05$ dan nilai $F$ hitung $0,024<0,05$. Dari hasil pengujian tersebut menunjukkan hipotesis diteriman dan sudah terbuktinya kebenarannya.

\section{IMPLIKASI}

Berdasarkan penulisan implikasi dari hasil penelitian yang dijelaskan diatas sebelumnya, maka dapat yang dapat disampaiakan sebaiknya manajemen perusahaan diharapkan akan melakukan usaha dalam meningkatkan produktivitas kerja karyawan dengan melalui layanan bimbingan kompetensi dan pengembangan kerja yang sistematis dengan baik. Bagi perusahaan juga lebih ditingkatkan lagi Kompetensi kerjanya dan pengembangan karir karyawan untuk mendapatkan produktivitas kerja yang tinggi dalam penyelesaian pekerjaan agar sesuai dalam mencapai tujuan.

\section{KETERBATASAN PENELITIAN}

Adanya keterbatasan responden yang diberikan oleh perusahaan. Perusahaan memberikan 70 responden.

Penyebaran kuisioner tidak dapat mendeskripsikan seluruh karyawan di perum JAMKRINDO (Jaminan Kredit Indonesia) Surabaya karena respondennya hanya pada satu devisi yaitu karyawan tetap.

\section{DAFTAR PUSTAKA}

Axchel, Tumiwa dkk, 2017. Pengaruh Teknologi Informasi,Lingkungan Kerja Dan Kompetensi Terhadap Produktivitas Kerja Karyawan. Vol.5 No.3 september 2017. Study Pada Kantor Pusat Bank Sulutgo.

Andi Budi dkk, 2016. Pengaruh Pengembangan Karir Dan Komunikasi Terhadap Komitmen Karyawan Yang Berdampak Pada Produktivitas Kerja. Vol.2 No.2 Maret 2016. Study kasus Karyawan di CV. Tirta Minerva Semarang.

CNN Indonesia, 2019, Pembangunan SDM Industri Kompetepada Revolusi Industri 4.0(http://www.cnnindonesia/nasional/20191102193618-293-445123/pembangunan-sdm-industrikompeten-pada-revolusi-industri-40, diakses pada tanggal 6 November 2019).

Dimas Jarot Bayu,2019,Nadiem Sebut SDM Indonesia Tak ProduktivitasKarena Lambat Bekerja (https://katadata.co.id/berita/2019/11/28/nadiem-sebut-sdm-indonesia-tak-produktif-karena-lambat-kerja, diakses pada tanggal 04 januari 2020). 
Dudung Abdullah. 2016. Pengaruh Pengembangan Karir Dan Kepuasan Kerja Terhadap Produktivitas Kerja Karyawan PT. Gistex Garment Indonesia Kabupaten Majalengka. Vol.3 No.2 JuliDesember 2016.

Dosen Fakultas Ekonomi. 2018. Pedoman Penulisan Skripsi. Edisi XII Th 2018. Universitas PGRI Adi Buana Surabaya. Persada.

Kasmir, S.E., M.M. 2018. Manajemen Sumber Daya (Teori Dan Praktek) Depok PT Rajagrafindo

Sutrisno M,Si. 2017. Manajemen Sumber Daya Manusia, Desain Cover, Circiestuff Design.

Samsul Bahri. 2016. Pengaruh Pengembangan Karir Dan Kompetensi Terhadap Produktivitas Kerja Serta Implikasinya Pada Kinerja Pegawai Dinas PU Bina Marga Wilayah Kerja Sumatera Selatan. Vol 1 No. 1 Februari 2016. 